\title{
A framework for understanding the website preferences of Egyptian online travel consumers
}

\section{Introduction}

The Internet has transformed marketing dramatically, in particular by providing interaction with consumers in any part of the world and in any language. Even in the early days of ecommerce, it was noted that users were three times more likely to buy a service or product when the web content was in their own language (DePalma, 1998). However, simply providing appropriate translations of web sites is insufficient for effective in-country digital marketing strategies, as cultural factors (the group of beliefs and values shared by a group) can also affect consumer interaction and need to be reflected in interface design. Providing such “Culturally congruent" (Luna et al., 2002, p. 400) content facilitates the consumer's processing of information and leads to more favourable attitudes towards the site and consequently the products/services being offered. This sensitivity to the consumer's culture also assists in personalisation of content, which leads to increased loyalty and sales (Singh et al., 2006; Tixier, 2005), while failure to reflect cultural values can lead to lost opportunities in attracting and keeping visitors engaged with content (Singh and Pereira, 2005b). This cultural sensitivity is of importance to the online travel market in Egypt, where both national and international travel companies seek to engage the growing Egyptian online consumer sector.

In order to understand how cultural values can be recognised and incorporated into digital offerings, a number of researchers and practitioners have tried to adapt various existing cultural frameworks, in particular those of Hofstede (1980), Hall (1977 and 1984) or Schwartz (1999), to online consumer behaviour and web design. The drawback to such an approach is that these cultural frameworks originally emerged from studies of organisational behaviour or communications theory, rather than consumer behaviour.

\section{The Emerging Egyptian Consumer}

Egypt has recently experienced rapid growth in Internet usage, doubling the number of users between 2006 and 2009 (World Development Indicators, 2010). Although, at the time of this writing the political situation is in turmoil, it is clear from the use of digital media during the "Arab Spring" and its aftermath, that digital media has become a vital part of Egyptian life and more attention needs to be paid by both local and international companies to attracting and engaging the Egyptian online consumer, in leisure travel and beyond. 
Egyptian culture is characterised by an awareness of Egypt's long history and its strategic location bordering Africa, Asia and Europe (Parnell and Hatem, 1999). Linguistic variations are often an expression of cultural variables, with Egyptian Arabic having a "focus on names, labels, family terms of respect, friendly and joking terms" (Feghali, 1997, p. 362) that is unique within Arabic-speaking countries. However, the studies of Hofstede and others have tended to adopt a monolithic approach to the concept of an "Arab" culture, rather than recognising the unique aspects of the Egyptian culture and how they could impact behaviour and communications.

Therefore, in order to develop effective and culturally-sensitive online travel marketing strategies and offerings for the Egyptian market, a cultural framework for web design is needed that is essentially grounded both in Egyptian cultural values and Egyptian online consumer behaviour. Such a framework should provide both researchers and practitioners with guidelines for assessing how such cultural values can impact on consumer behaviour and how to develop digital platforms that promote consumer engagement by recognition and reflection of these values. This paper details the development of such a framework, named the E-CAF (Electronic Cultural Adaptation Framework), and how this framework enhances our understanding of Egyptian online travel consumers, although this understanding can potentially be extended to other cultures and domains.

\section{Culture and web design}

The common approaches to assessing the effect of cultural values on online consumers tend to concentrate on aspects of web design, either adapting existing cultural models to web design or focusing on cultural symbols as a factor in web design.

Those approaches that adapt existing cultural models, tend to rely on one or more of the following models:

- Hofstede's five dimensions of culture variability -- individualism-collectivism (IDV), low-high uncertainty avoidance (UA), low-high power distance (PD), masculinityfemininity (MAS) (Hofstede, 1980) and short-term vs. long-term (TO) orientation (Hofstede 1991, 2001).

- Hall's context model (1984), which differentiates those cultures that are Low-Context (preferring communication that is explicit, direct, and unambiguous, from HighContext (those that prefer a more nonverbal mode of communication. Hall's context model is often used as a complement to Hofstede's work. 
- Schwartz's (1999) seven dimensions of cultural variation: -- Conservatism (CM), Intellectual autonomy (IA), Affective autonomy (EA), Egalitarian commitment (EC), Harmony (H), Mastery (M), Hierarchy (HY).

Examples of adapting existing cultural models to web design using Hofstede's framework include Singh and Pereira (2005), Singh et al. (2008) and Gong et al. (2007). A more recent example of the Hofstede-based approach is Baack et al. (2013), who use Singh and Pereira's (2005) framework to measure cultural reflection on web content. However, this work is based on a survey that included only 11 items to measure cultural dimensions. Others have tried to synthesise two or more existing cultural models, such as Hofstede's and Hall's, to explain the impact of culture on Web usage, such as Zahedi et al. (2001) and Hermeking (2005).

Many researchers now question if the Hofstede framework can still be applied to assess the cultural dimensions on web interface. In their 2013 work, Singh, Park and Kalliny develop a framework to assess the cultural factors affecting B2B Web content. Their B2B web localization framework is divided into three dimensions (p. 57),

- "Context localization" to focus on trust elements to enhance communication,

- "Content localization" to focus on web site elements that need to be adapted,

- "Cultural localization" to focus on adapting site content to cultural expectations of the targeted society.

This work is a step toward developing a unique model that could be used to assess the cultural dimensions affecting Web sites, but the study's main aim is to assess the cultural factors affecting B2B Web sites. At the end of their work, Singh, Park and Kalliny (2013) critique their research, saying that their study "tells us what is there but does not tell us why a certain phenomenon exists" (p.73).

The second approach to understanding culture and Web interface is to utilise various interface design features to assess cultural preferences amongst users, including language (Gibb and Matthaiakis, 2007), colour (Barber and Barber, 1998; Duncker et al., 2000) and animated banners (Noiwan and Norcio, 2006).

Unfortunately, both of these approaches have a number of drawbacks. The use of existing cultural frameworks, whether a single one or a combination thereof, to understand Web behaviour neglects consumer behaviour overall and ignores cultural perception of web design features such as navigation styles, colours and symbols. Adding to this drawback is the question of which framework to choose. $\mathrm{Ng}$ et al. (2006) contend that the standard cultural 
frameworks provided by Hofstede, Schwartz etc. are not congruent, and warn that researchers should carefully consider which cultural base is most appropriate for use in any study.

If the adaption of existing cultural models neglects consumer behaviour and values, a focus on cultural perception and the symbolism within interfaces ignores aspects of both cultural and consumer behaviour. Language-specific approaches in particular do not accurately reflect cultural values (Evers, 1998).

More integrated approaches, linking both existing cultural frameworks and web design factors, have been presented. The Marcus and Gould (2000) framework links Hofstede's cultural dimensions and characteristic factors of user interfaces, while Singh et al. (2003) also incorporate Hall's work. Empirical testing has demonstrated that either of these frameworks can provide insights into how different cultures use web sites (Callahan, 2005; Singh et al., 2005a), for example demonstrating that high Uncertainty Avoidance cultures often dislike many hypertext links on a page (Burgmann and Kitchen , 2006), or clearly showing cultural differences in American versus Mexican web designs (Singh and Baack, 2004) or presenting how choices in navigation and types of images differ in High Context versus Low Context cultures (Würtz, 2005).

However other studies have shown significant limitations in use of these integrated frameworks, either through difficulties in implementation (Dormann and Chislita, 2002), or applicability in particular countries (Sinkovics et al., 2007). In addition, much of the analysis in these studies is on the websites themselves, in effect focusing on the cultural values of the web designer rather the user of those sites. Moreover, all of these studies focus on Western and Asian cultures while other cultures, most notably Egyptian and other Arab cultures, are ignored.

Perhaps the biggest concern is that, regardless of derivation, the cultural frameworks that underpin these studies are generally those of Hofstede, Hall and/or Schwartz. Hofstede's model in particular is one of the most popular models in marketing research, despite the fact that this model was originally built to assess work cultural values (Soares et al., 2007), which should raise doubts about its applicability for marketing research. Hall's model is aimed at identifying communication patterns across cultures, while concerns have been raised about the applicability and validity of Schwartz's model in a marketing context (Watson and Wright, 2000), which may be due in part to the scattered findings of Schwartz across large number of publications (Okazaki and Mueller, 2007). Most significantly of all, despite the recognition that "A comprehensive cultural customization will reflect three levels of cultural adaptation: perception, symbolism, and behaviour" (Singh and Pereira, 2005b, p. 14), none of 
these frameworks recognise the cultural aspects of consumer behaviour overall, let alone domain-specific behaviour. Sachau and Hutchinson (2012) have argued that the best way to develop a web localization framework suitable for assessing web cultural content is to deeply investigate the Web users' preference, perceptions and opinion.

In examining the effect of culture on specifically travel shopping, Au, Law and Buhalis's (2010) work examines the effect of culture on online consumer complaints through the analysis of Hong Kong hotels' Web sites. However, this work was based on content analysis of hotels websites, rather than any study of the online consumers' perceptions and preferences. At the end of their research, Au et al. concluded that a more comprehensive framework is needed to identify different patterns of consumers' cultural behaviour within the travel domain sector.

\section{Tourism sector and online information searching}

Despite the clear importance of understanding searching behaviour within the tourism sector, there has historically been little research into online searching behaviour specifically in this sector. Tierney (2000) shows that the most common travel-related searching behaviour includes trip activities, attractions, maps, shopping, special events, festivals and accommodation. Similarly, Chu (2001) demonstrates that travellers who visited airline sites expect information on destinations, local activities, hotel booking, special trip packages, weather conditions, car rental, entertainment guides, souvenirs, gifts, bonus mileage, train passes and travellers cheques.

Both Pan and Fesenmaier (2006) and Toms et al. (2003) argue that online search behaviour will vary based on the consumer's levels of experience across different domains and suggest that the interaction should be personalised for easy mental interface processing. Pan and Fesenmaier describe the mental model online travel consumers manifest when searching, which is based on their previous online travel experiences. This model indicates that these consumers follow a hierarchical process for vacation planning, including different decisions and sub-decisions with varied rigidity level.

In a study of culturally-related search behaviour, Evers (2001) claims that the collectivist nature of Japanese participants conflicts with the individualistic nature of the search task, resulting in research participants being unable to manifest a specific searching approach. Evers suggests that it would therefore be useful to provide local problem solving support when localising Japanese Web interfaces. Moreover, Evers states that different cultural 
groups have different patterns of Web navigation and in particular both Dutch and Japanese consumers demand more detailed information and pictures.

\section{Research methodology}

In order to determine how to best understand what constitutes culturally-sensitive platforms for online travel marketing in Egypt, the researcher faces the challenge of how to incorporate the domain-specific cultural values and web site preferences of Egyptian consumers. This necessitates a methodology that does not exclusively rely on generic cultural frameworks, but instead utilises an ethno-consumerist perspective (Meamber and Venkatesh, 2000) to capture the unique cultural dimensions of Egyptian consumption behaviour. By incorporating methods such as ethnography and grounded theory, as well as relevant aspects of the generic cultural frameworks, a better and deeper understanding of the cultural variables influencing consumers' behaviour can be achieved. This understanding can then, in turn, produce a suitable culturally-relevant framework for digital marketing design.

Given the requirement to construct a theoretical framework that will explain online consumer behaviour in an Egyptian cultural context, the decision was taken to use an abductive approach. In this approach, the researcher examines observed data to develop explanations for that data, and then forms hypotheses until arriving at the best plausible interpretation for the data (Charmaz, 2006). Grounded Theory as depicted by Strauss and Corbin (1998) is particularly suitable for construction of theoretical frameworks from an abductive approach which are grounded in both the data and existing theory (Shaw, 2003), and was therefore chosen for this research. Grounded theory has also been successfully used as a methodology to study culture in organisations (Pearse and Kanyangale, 2009), consumer experience (Goulding, 2002; Goulding and Saren, 2010) and tourist behaviour (Riley, 1996). Pearse and Kanyangale in particular contend that grounded theory is an effective tool for cultural research as it allows the development of contextual understanding of behaviour and interaction within cultural and social communities.

To further explore limitations of previous research (in particular the neglect of Egyptian culture), the participants in this research were native-born Egyptians who had not spent more than 5 years outside the country, and with at least some experience in online shopping. Participants were recruited using Egyptian University networks and Egyptian IT Centres using snowball sampling. Due to the violent civil unrest occurring in Egypt during part of the data gathering activity, the decision had to be taken to minimise risks to researchers and participants alike by including seven participants who were currently in the UK but otherwise 
met the criteria for participation as they had not previously resided overseas and were only in the UK for postgraduate studies. Berry (2006) contends that "sojourners" (p. 30), those who are only in a country on a temporary basis in a set role, often show little desire to engage with a new culture. This is demonstrated by the fact that the UK participants recruited for this study lived and socialised in Egyptian-centred communities in London, underscoring their desire to retain their Egyptian attachment and identity (Kilduff and Corley, 1999). It was recognised that there was some risk these participants could have been influenced by their time in the UK, however in fact the data gathered from these participants proved to be virtually the same as those currently located in Egypt, aside from one minor aspect which will be discussed later in this paper. All participants were observed in person by a native Egyptian researcher, who audio-recorded all sessions and interviews.

In the observation sessions, each participant was shown a list of travel sites, some of which were operated by Egyptian-based travel companies and others by international travel companies specifically targeting Egyptian consumers (e.g. Thomas Cook Egypt). Participants were requested to select the one site they were least familiar with. They were then asked to research a leisure trip of their choice and gather as much information as they would need to decide on their trip. During the observation sessions participants were encouraged to verbalise their actions and thoughts while using the site. After the observation session, each participant was then interviewed by the Egyptian researcher concerning previous online travel shopping experiences, feelings and preferences.

Recordings of the observation sessions and interviews were coded by the Egyptian researcher using NVIVO software after each group of 5 observations/interviews. Coding of the first group resulted in 58 open codes. The mapping of open to axial codes in Grounded Theory is described by Goulding (2002, p. 78) as “... specifying relationships and delineating a core category or construct around which the other concepts revolve". Using this approach, the relationship between the 58 open codes were carefully examined and grouped into common themes. For example, the open codes of "Family Holidays", "Viewing family attractions" and "family trip planning" identified in the first group were mapped into an axial code named "Family Orientation". In total, the 58 open codes were mapped to 16 axial codes.

Coding of the second group produced 24 new open codes which were mapped to the existing 16 axial codes plus one new axial code. Coding of the third group produced 6 new open codes which all mapped to the existing axial codes, while coding of the fourth group produced no new codes, thereby achieving theoretical saturation after 20 participants, well 
within the accepted parameters for this type of study (Guest et al., 2006). In Grounded Theory methodology, when "no new evidence emerges which can inform or underpin the development of a theoretical point" (Goulding, 2002, p. 70) the set of axial codes developed can then be contextualized against the existing literature to establish a set of theoretical categories. The 17 axial codes derived in this research were consequently combined into six theoretical categories as shown in Table 1.

\begin{tabular}{|c|c|}
\hline Axial codes & Theoretical categories \\
\hline $\begin{array}{ll}\text { - } & \text { Accurate destination information } \\
\text { - } & \text { Guidance } \\
\text { - } & \text { Reliability } \\
\text { - } & \text { Metaphor usability } \\
\text { - } & \text { Metaphor clarity } \\
\text { - } & \text { Predictability } \\
\text { - } & \text { Risk avoidance factors }\end{array}$ & High Risk vs. Low risk Concern \\
\hline $\begin{array}{l}\text { - } \quad \text { Customer involvement and relations } \\
\text { - } \quad \text { Encouraging relations between users. }\end{array}$ & Emotional vs. Functionality \\
\hline $\begin{array}{ll}\text { - } & \text { Family orientations } \\
\text { - } & \text { Group and family themes } \\
\text { - } & \text { Interface group harmony }\end{array}$ & Family/Group vs. Individual role \\
\hline $\begin{array}{ll}\text { - } & \text { Emotional dependency support } \\
\text { - } & \text { Cognitive dependency support }\end{array}$ & Dependence vs. Independence \\
\hline $\begin{array}{l}\text { - } \quad \text { Image and video processing } \\
\text { - } \quad \text { Aesthetic concerns }\end{array}$ & Visual vs. Lexical context role \\
\hline $\begin{array}{ll}\text { - } & \text { Spoken word } \\
\text { - } & \text { Word of mouth }\end{array}$ & Oral vs. Written Communication \\
\hline
\end{tabular}

Table 1 - Axial Codes and Theoretical Categories

Following Grounded Theory evaluation methodologies, the resulting framework was validated via Expert Review, whereby practitioners in various Egyptian travel agencies and Web design companies were shown the framework and asked to evaluate its usefulness as a tool for strategy and/or site design in the industry. This evaluation confirmed the framework's Usefulness and Originality (Charmaz, 2006), External Credibility (Patton, 2002) and Applicability (Goulding, 2002).

To further evaluate both Usefulness and Applicability of the framework three other travel web sites targeted towards Egyptian consumers were evaluated by the researchers using guidelines derived from the framework. The results of this evaluation were presented at a 
conference on E-Commerce research for further feedback and commentary (Hagag et al., 2011).

\section{Research findings: the E-CAF}

The results of the Grounded Theory research produced six theoretical categories as shown in Figure 1.

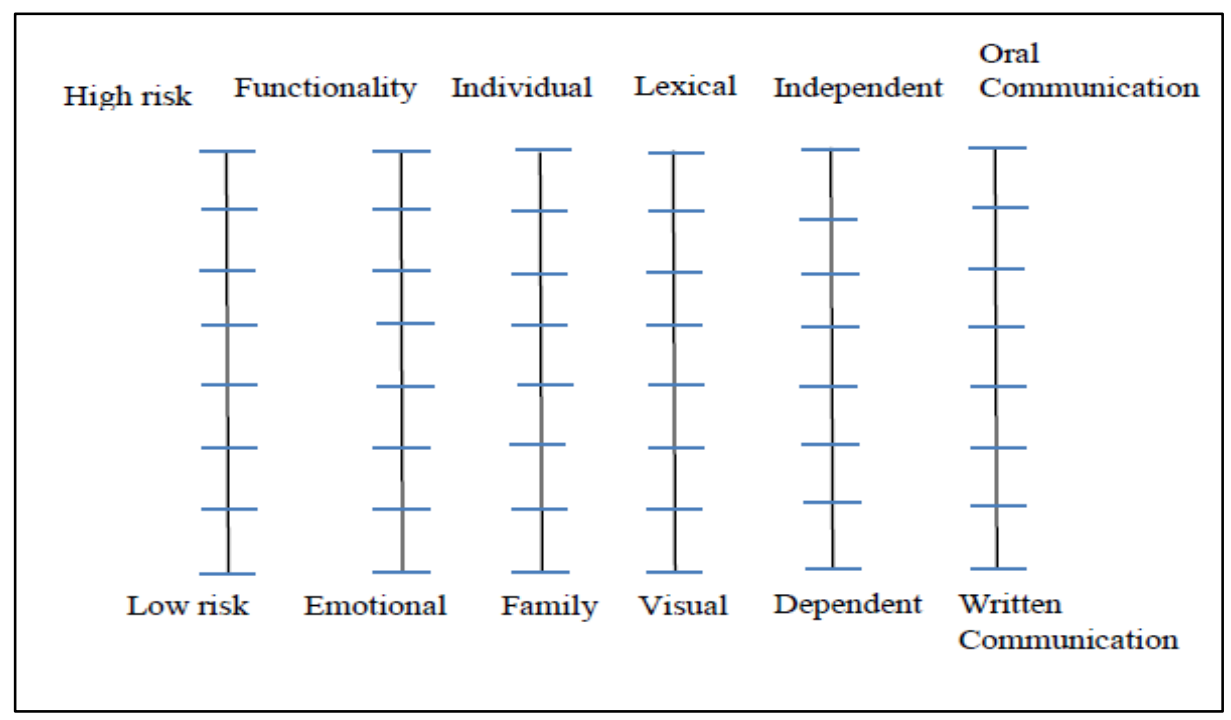

Figure 1 - The E-Cultural Adaption Framework (E-CAF)

This visual representation of E-CAF shows a vertical continuum for each cultural category. The horizontal bars shown in each cultural category continuum represent the relative levels of each category that can exist within a culture. A description of each category follows.

\section{High versus Low Risk concern.}

This category is a factor cited throughout the literature, and is closely related to Hofstede's "Uncertainty Avoidance" dimension. Reisinger and Turner (1999) used Hofstede's dimension to justify the increased need within specific cultural groups for accurate and reliable trip information. It has been noted by Money and Crotts (2003) and Litvin et al. (2004) that travel consumers from a high Uncertainty Avoidance culture prefer to manage all their trip planning and bookings in advance, and such consumers prefer shorter trips if going to unfamiliar destinations. Marcus and Gould (2000) argue that Web interfaces should be adapted based on a familiar users' mental model and clearer metaphor to minimise the risk concern of the targeted cultural group. This is confirmed by Singh et al. (2005c) who state that a clear metaphor is an important aspect of Web localisation for high uncertainty avoidance cultures and can be achieved through guided navigation to minimize the users' risk 
concern. They provide some general factors that can be considered for Web localisation to minimise the risk concern across high uncertainty avoidance cultures such as using FAQs, providing customer service support and providing users with local store contacting details.

This research revealed that through their demand for detailed information, metaphor clarity and metaphor usability Egyptian travel consumers can be considered high risk concern consumers. The participants demanded highly detailed information on various aspects such as background and history of destinations, attractions near hotels, and local cuisine and were also concerned with ranking of hotels, a demand which has been proven to be an indicator of high risks concerns in travel consumers (Mitchell and Vassos, 1997).

"It is very annoying, how come a tourist site does not present a list of different destinations and attractions on their page? These should be easily accessible at first glance." (Participant 2)

In terms of clear metaphors, participants perceived roll-over menus as "hidden submenus" (Participant 10) which were strongly disliked. Menus and icons on pages that were only visible after scrolling were also perceived as "hidden" and naturally produced negative reactions.

"I do not like any hidden icons [sic]. I prefer everything to be in front of my eyes." (Participant 7)

Participants demonstrated their need for advanced planning by being highly sceptical of last-minute deals.

"For travelling you cannot leave it until the last second. Everything needs to be planned in advance. It is risky to leave things until the last minute" (Participant 13)

However, different levels of risk concern were demonstrated by the participants, as those who had lived their entire life in Egypt expressed a higher level of risk concern compared to those who were currently residing in the UK. One manifestation of this difference was the desire of the first participant group to use telephone booking, compared to the second group who were more willing to book online. It is unclear whether this willingness to book online was due to the exposure of the second group to UK culture, which is characterised by low uncertainty avoidance, or simply having done more shopping on UK websites, which would suggest that experience with online shopping can, over time, reduce culturally-based risk avoidance behaviours (Park and Jun, 2003). It should be noted that this was the only area in 
which there was any noticeable difference between the participants located in the UK and Egypt.

\section{Emotion versus Functionality}

This category describes cultures that value emotional versus functional and informational appeal. Reisinger and Turner's (1999) study revealed that travel consumers who are part of a culture manifested by Hofstede's "Feminine" category often show interest in building warm and friendly relations, and this difference is supported by Sigala and Sakellaridis (2004). Singh et al. (2005c) state that cultures demonstrating Hall's High Context category require a softer selling approach, using artefacts such as a "greeting from the company" and stressing the importance of "subjective impressions" on consumers from such cultures.

A high emphasis on personal relationships in communication is a hallmark of Arab cultures in general, including Egypt (Yasin and Yavas, 2007) and this research demonstrated that the participants valued the emotional appeal of Web interfaces and desired more personable interactions with vendors.

"Many offers and deals are located on the home page. I think it is better if they start with a little bit about themselves as an introduction." (Participant 5)

"The phone is friendlier, you can engage in conversation with a real person, which is warmer." (Participant 4)

Participants valued customer relationships not only with the vendors, but each other, expressing preferences for sites that encouraged sharing of information.

"I think it would be a good idea if the site provided a chance to post other tourists" experiences, photos. In addition, allowing the chance to contact other tourists through email provides a good chance to contact them personally asking about their own experience." (Participant 5)

Interestingly enough, there was considerable resistance to links that asked for direct customer feedback, as this was seen as presuming on a friendly relationship.

\section{Family/Group versus Individual}

This category describes the how the participant's decision-making process is adjusted based on family/group versus individual interests. This category is related to Hofstede's "Collectivism/Individualism" dimension, but also the "Feminine/Masculine" dimension as well. Yates and Lee (1996), noticed that consumers in cultures that favoured groups/family often adjust their behaviour to match group interest instead of cognitive conclusions. 
Consumers from such cultures have been shown to prefer travelling with group or family members (Reisinger and Turner, 1999; Cho, 2006; Pizam and Jeong, 1996), and are attracted to family-themed sites and harmonious information and links (Singh et al., 2003).

This research indicated that the participants strongly valued the group interest, as manifested through their preference of family themes and harmonious Web interfaces. Family holidays were clearly preferred, and decisions needed to be taken with the family.

"I prefer to plan my trip together with my family members, this allows opinion sharing about the best place to visit. We need to agree on a place that satisfies all the family members." (Participant 6)

Websites that reflected family themes were strongly preferred.

"I love pictures of a beach surrounded by buildings and people, they look warm and lovely. It is nice to be with people. I noticed that a lot of tourist sites prefer to place an empty beach picture! The empty beach pictures are unattractive; they reflect a remote place. I would not be interested at all to visit such a place." (Participant 2)

\section{Dependency versus Independence}

This category describes cultures in which personal decisions need to be confirmed by others for personal security, versus cultures where personal decisions are based on self-experience and trust. In discussing this category, it is useful to include both cognitive dependency, where someone desires informational support in decision making activities, as well as emotional dependency, where the "ongoing presence and nurturing of another is believed to be necessary for personal security" (Rentzel, 1990, p. 7). Despite the fact that the concept of dependency has been previously incorporated into social and clinical psychology fields (Bornstein, 1993) it is relatively new to cultural understanding of consumer behaviour. Dependency as a cultural variable has been identified by Browne (2006), however this category does not have a clear equivalent to the generic cultural categories of Hofstede, Hall, etc. De Luque and Sommer (2000) and Zaheer and Zaheer (1997) argue that consumers in high Uncertainty Avoidance cultures often exhibit cognitive dependency of thought, while other researchers, such as Kirby (2000), claim that dependency is often demonstrated in High Collectivist cultures, where members are reliant on families for longer periods. Kirby also contends that cognitive dependency in particular may be a result of a country's educational system. 
This research revealed that the participants manifested not just cognitive but also emotional dependency. In terms of cognitive dependency, the participants clearly wanted the vendors to provide not only ideas and plans for trips, but also suggestions for gifts to bring back.

"I should be able to depend on the travel site for planning a nice trip programme, especially a good one for a family trip." (Participant 3 )

Participants also expressed a high level of emotional dependency, in particular receiving confirmation from peers that they had made the right travel choices.

"I like to check other tourist reviews and comments regarding each destination. I depend on these comments to...assess the most suitable places for me to visit." (Participant 5)

One interesting phenomena of this level of dependency was participants often took exception to expressions on the vendor sites that seemed to encourage independence.

“The site used bad link titles such as 'plan your trip'. This means hard effort needs to be done while I need to enjoy and relax." (Participant 6)

\section{Visual versus Lexical Content}

This category describes the amount of interactive images and media vs. text on a local Web interface and is related to Hall's "Context" model. Singh et al. (2005c) use Hall's model to justify highly aesthetic web designs for consumers belonging to High Context cultures, while suggesting a greater concentration on textual and informational interfaces for consumers from Low Context cultures. Similarly, Rayport and Jaworski (2001) distinguish between aesthetics and functional Web site orientation as two approaches for designing Web interfaces, with an emphasis on multimedia and animation for the aesthetic orientation. Zaharna (1995) states that Arab consumers, including those in Egypt, are found to focus more on symbolism rather than the analytical content of a message, suggesting that Egyptian online consumers would gravitate towards an aesthetic web design.

This research revealed that the participants were much more attentive to the aesthetic details of a site rather than textual information.

"Unfortunately, this site has a large amount of text. I will never read all of that information. Why not replace that text with some more attractive pictures?" (Participant 3) 
Participants preferred not only pictures of sites, but also multimedia artefacts where possible.

“This site isn't attractive at all, they need more pictures with some audio and flashing animation. This will make the site more attractive and enjoyable while using it." (Participant 6)

Colour was also important, with participants expressing more comfort with sites that used warmer colours (e.g. red, yellow and orange), while varied text styles were also preferred.

"The text font should be clear with various sizes and colours to make it more realisable [sic]." (Participant 7)

\section{Oral versus Written Communication.}

This category describes cultures that rely on oral versus those that prefer written communication. This category is related to Hall's Context model, which has been used by a variety of researchers (Yasin and Yavas, 2007; Zaharna, 1995; Singh et al., 2005) to describe culturally-preferred communication strategies, with those cultures considered High Context preferring oral communication. Zaharna, along with Yasin and Yavas, characterise Arab cultures in particular as oral dominant, preferring face-to-face communication, and oral dominant consumers, regardless of cultural background, are more likely to engage in wordof-mouth behaviour, especially if they want to express negative feedback (Kacen and Lee, 2002).

This research revealed that the participants valued oral over written communication, preferring to speak to vendors where possible.

"I get really annoyed if I cannot find a customer service contact number or online chat support on this site, this stops me from using the site....you can speak with a real person and have a conversation until you are completely satisfied.” (Participant 14)

As per Kacen and Lee's observations, participants were more willing to provide feedback via recommend-a-friend link, but were extremely reluctant to fill out any surveys or other requests for feedback that came directly from the vendor.

"I think they [the vendor] should consider that they will never get their customers' real opinion or experience by directly asking them to fill out a survey or by writing their comments." (Participant 9) 


\section{The contribution of the E-CAF to theory and practice}

As discussed in the Literature Review, neither Hofstede's and Hall's cultural models are sufficient for understanding or categorising Egyptian cultural variations in web site design preferences as these models were derived from organisational behaviour and marketing communications respectively. The more recent frameworks of Singh et al. and Marcus and Gould, while providing useful guidelines for web design, depend on cultural frameworks that are not derived from Egyptian consumer behaviour or web preferences. To address these shortcomings, the E-CAF incorporates relevant work in cultural frameworks with an understanding of Egyptian online travel consumer behaviour to produce a framework that can provide new insights into designing effective web sites. One example of these new insights are the ones provided by the Dependency/Independency category, as this has a clear impact on our understanding of online consumer behaviour within the Egyptian culture, but is not clearly reflected in the established cultural frameworks.

The E-CAF has a number of practical contributions as well. When presented to Egyptian marketing practitioners for Expert Review, they quickly recognised the benefits the framework could provide them for developing online strategies. For example, the Oral versus Written communication category helped the marketing practitioners to understand why their efforts to solicit feedback via online surveys had not been successful. The E-CAF category that engendered particular enthusiasm amongst practitioners was the Dependency/Independency category. As one expert said, “A 'dependent' consumer? Oh, it is a good description of the Egyptian consumer!" The web design companies participating in the Expert Review of the E-CAF recognised its contribution to their work, in particular using questions derived from the E-CAF to help define client requirements but also serving as an overall guideline in site design considerations.

\section{Conclusions}

This research set out to understand the website preferences of Egyptian consumers within a specific shopping domain, online travel. Using the E-CAF, designers of online travel sites aimed at the Egyptian consumers can more fully understand their users and develop effective and engaging websites. This contribution has been recognised by a panel of Egyptian online travel companies, who found the description of the Egyptian consumer as a "dependent" consumer particularly enlightening. Using design guidelines derived from the E-CAF, websites can be assessed as to their suitability for the Egyptian travel market and impediments to the Egyptian user experience can be identified, such as clear and highlighted 
inclusion of telephone contact information (Hagag, 2011). While the E-CAF provides a number of contributions to understanding Egyptian online travel consumers and their web design preferences, to truly assess the value of this new framework, the E-CAF would need to be validated across other Egyptian shopping domains.

While this paper has argued that Egyptian culture needs to be specifically considered in website design for Egyptian consumers, it is also recognised that Egyptian culture has a significant impact on the rest of the Arab world, as demonstrated by the influence of Egyptian literature and cinema in the Middle-East. This suggests that aspects of the E-CAF could be applicable in other Arab countries, but again this would need to be demonstrated by countryspecific research.

Another consideration is that of the nature of "culture" itself. This study has considered culture as a set of shared values, attitudes and behaviours, as these have particular influence on consumer behaviour (Terlutter et al., 2005). Such an understanding of culture must therefore recognise that these shared attributes can and will evolve over time, and therefore any insights gained by use of the E-CAF would need to be re-evaluated on a periodic basis. It is also clear from the E-CAF experience that a nationalistic definition of culture can be problematic - for example, it had been previously observed that Egyptians who had spent more than 5 years outside their country exhibited different online shopping behaviours from their in-country colleagues and were therefor excluded from this study. Within this study, the use of some participants who were currently based in the UK raises concerns whether those participants were somehow influenced by UK culture. As previously stated, the data extracted from these participants did not significantly differ from the Egyptian-based ones aside from concerns over Risk. Whether this is an influence of being specifically in the UK, or simply being outside of Egypt is unclear, but does suggest that studies of Egyptians who are longterm residents of other countries would shed light on the extent to which culture-based website preferences are affected by prolonged exposure to other cultures.

Finally, this research is, above all else, a call to online marketing researchers and practitioners to remember that while Digital Marketing is a global phenomena, cultural variations still exist amongst online consumers, in Egypt and elsewhere, for online travel and other domains. These cultural variations affect both consumer and vendor viewing, communication and interaction preferences, and effective Digital Marketing depends on the extent to which researchers and practitioners alike can understand and incorporate these variations. 


\section{References}

$\mathrm{Au}$, N., Law, R. and Buhalis, D. (2010), "The impact of culture on eComplaints: Evidence from Chinese consumers in Hospitality Organisations", in Gretzel, U., Law, R., Fuchs, M., (eds), ENTER 2010 Proceedings, Lugano, Springer-Verlag, Wien, ISBN: 9783211994061, pp.285-296.

Baack, D., Singh, N. and Baack, D. (2013) Culturally Customizing Websites for Immigrant Communities in the United States. Journal of Promotion Management, Vol.19 No.1, pp. 3853.

Barber, W. and Barber, A. (1998), "Culturability: The Merging of Culture and Usability", paper presented at 4th Conference on Human Factors \& the Web, June $5^{\text {th }} 1998$, Basking Ridge, New Jersey, USA, available at http://research.microsoft.com/enus/um/people/marycz/hfweb98/barber/index.htm (accessed 25 October 2012)

Berry, J. W. (2006), “Contexts of acculturation”. In D. L. Sam \& J. W.Berry (Eds.), The Cambridge Handbook of Acculturation Psychology, Cambridge University Press, New York. pp.27-42.

Bornstein, R. (1993), The dependent personality, The Guildford Press, New York.

Browne, K. (2006), Introducing Sociology for AS Level (2nd ed.). Polity Press, Cambridge UK.

Burgmann, I., Kitchen, P. J. (2006), "Does culture matter on the web?", Marketing Intelligence \& Planning, Vol. 24 No. 1, pp. 62-76.

Callahan, E. (2005), "Cultural Similarities and Differences in the Design of University Web sites”, Journal of Computer-Mediated Communication, Vol. 11 No. 1, pp. 239-273.

Charmaz, K. (2006), Constructing Grounded Theory. A Practical Guide Through Qualitative Analysis, Sage, London.

Cho, M. (2006), "A Re-Examination of Cultural Influences on Restaurant Tipping Behaviour", Journal of Foodservice Business Research, Vol. 8 No. 1 pp. 79-96.

Chu, R. (2001). What do on-line Hong Kong travelers look for on airline/travelWeb sites?

International Journal of Hospitality Management , 20, 95-100.

De Luque, M.F.S. and Sommer, S.M. (2000), "The Impact of Culture on Feedback-seeking Behaviour: An Integrated Model and Propsitions", Academy of Management Review, Vol. 25 No. 4, pp. 829-849.

DePalma, D. (1998), Strategies for Global Sites, Forrester Research, Cambridge.

Dormann, C. and Chisalita, C. (2002), "Cultural values in Web site design", 11th European Conference on Cognitive Ergonomics. Catania.

Dormann, C. and Chisalita, C. (2002), “Cultural values in web site design". Paper presented at ECCE-11: Eleventh European Conference on Cognitive Ergonomics, September 8-11, 2002, Catania, Italy.

Duncker, E., Theng, Y.L. and Mohd-Nasir, N. (2000), "Cultural usability in digital libraries", Bulletin of the American Society for Information Science and Technology, Vol. 26 No. 4, pp 21-22.

Evers, V. (1998), "Cultural Differences in Understanding Human Computer Interfaces" Cultural differences in Understanding Human Computer Interfaces, an Open University CITE report, The Institute of Educational Technology, the Open University, Milton Keynes, UK. 
Evers, V. (2001). "Cultural Aspects of User Interface Understanding: An Empirical Evaluation of an E-Learning Web site by International User Groups". PhD Thesis, University of Amsterdam.

Feghali, E. (1997). "Arab cultural communication patterns", International Journal of Intercultural Relations, Vol. 21 No. 3, pp. 345-378.

Gibb, F. and Matthaiakis, I. (2007). "A framework for assessing Web site localisation" The Electronic Library, Vol. 25 No. 6, pp. 664-678.

Gong, W., Li, Z.G., Stump, R.L. (2007) "Global Internet use and access: cultural considerations", Asia Pacific Journal of Marketing and Logistics, Vol. 19 No. 1, pp. 57-74.

Goulding, C. (2002), Grounded Theory. A Practical Guide for Management, Business and Market Researchers, Sage, London.

Goulding, C. and Saren, M. (2010), "Immersion, emergence and reflexivity: grounded theory and aesthetic consumption", International Journal of Culture, Tourism and Hospitality Reserch, Vol. 4 No. 1, pp.70-82.

Hagag, W., Clark, L. and Wheeler, C. (2011) "E-CAF: examining the adaptation of local travel interfaces", paper presented at 2011 Networking and Electronic Commerce Research Conference (NAEC2011), 13-16 October 2011, Riva del Garda, Italy.

Hall, E.T. (1977), Beyond Culture. Doubleday, New York.

Hall, E.T. (1984), The Dance of Life: The Other Dimension of Time, Anchor Books, New York.

Hermeking, M. (2005), Culture and Internet consumption: Contributions from cross-cultural marketing and advertising research, Journal of Computer-Mediated Communication, Vol. 11 No. 1, Article 10, available at http://jcmc.indiana.edu/vol11/issue1/hermeking html (accessed October 19, 2009).

Hofstede, G. (1980), Culture's Consequences, Sage Publications CA, Beverley Hills.

Hofstede, G. (1991), Cultures and Organizations: Software of the Mind: Intercultural cooperation and its Importance for Survival, McGraw-Hill International, New York.

Hofstede, G. (2001). Culture's Consequences (2nd Edition). Sage Publications, Thousand Oaks, CA.

Kacen, J.J. and Lee, J.A. (2002), "The Influence of Culture on Consumer Impulsive Buying Behaviour", Journal of Consumer Psychology, Vol. 12 No. 2, pp. 163-176.

Kilduff, M. and Corley, K.G. (1999), "The Diaspora Effect: The Influence of Exiles on Their Cultures of Origin”,M@n@gement, Vol.2 No.1,pp1-12.

Kirby, M. (2000), Sociology in perspective, Heinemann, Oxford.

Litvin, S.W., Crotts, J.C. and Hefner, F.L. (2004), "Cross-cultural tourist behaviour: a replication and extension involving Hofstede's uncertainty avoidance dimension", International Journal of Tourism Research, Vol. 6 No. 1, pp. 29-37.

Luna, D., Peracchio, L.A. and de Juan, M.D. (2002), "Cross-cultural and cognitive aspects of Web site navigation", Journal of the Academy of Marketing Science, Vol. 30 No. 4, pp. 397410 .

Marcus, A., \& Gould, E.W. (2000), "Cultural dimensions and global Web user-interfacedesign: What? So what? Now what?", presented at the 6th Conference on Human Factors and 
the Web, June 19 2000, Austin, Texas, USA, Available at http://idealgroup.org/demonstrations/hfweb00.marcus.html (October 25 2012).

Meamber, L. and Venkatesh, A. (2000), "Ethnoconsumerist Methodology for Cultural and Cross-Cultural Consumer Research", in Beckmann, S. A. and Elliot, R. (Eds.), Interpretive Consumer Research : Paradigms, Methodologies \& Applications, CBS Press, Copenhagen, pp. 87-108.

Mitchell, V.M. and Vassos, V. (1997), "Perceived Risk and Risk Reduction in Holiday Purchases: A Cross-Cultural and Gender Analysis", Journal of Euro-Marketing, Vol. 6, No. 3. pp. 47-79.

Money, R.B. and Crotts, J.C. (2003), "The effect of uncertainty avoidance on information search, planning and purchases of international travel vacations", Tourism Management, Vol. 24 No. 2, pp. 191-202.

Ng, S. I., Lee, J.A. and Soutar, G.N. (2006), "Are Hofstede's and Schwartz's value frameworks congruent?”, International Marketing Review, Vol. 24 No. 2, pp. 164-180.

Noiwan, J. and Norcio, A.F. (2006), "Cultural differences on attention and perceived usability: Investigating color combinations of animated graphics", International Journal of Human-Computer Studies, Vol. 64 No. 2, pp. 103-122.

Okazaki, S. and Mueller, B. (2007), "Cross-cultural advertising research: where we have been and where we need to go", International Marketing Review, Vol. 24 No. 5, pp. 499-518.

Pan, B. and Fesenmaier, D.R. (2006), “Online Information Search: Vacation Planning Process", Annals of Tourism Research, Vol. 33 No. 3, pp. 809-832.

Park, C. and Jun, J.K. (2003), “A cross-cultural comparison of Internet buying behaviour”, International Marketing Review, Vol. 20 No. 5, pp. 534-553.

Parnell, J.A. and Hatem, T. (1999), "Cultural Antecedents of Behavioural Differences between American and Egyptian Managers", Journal of Management Studies, Vol. 36 No.3, pp. 399-418.

Patton, M. (2002), Qualitative research and evaluation methods (3th ed.), Sage Publications, USA.

Pearse, N. and Kanyangale, M. (2009), "Researching Organizational Culture Using the Grounded Theory Method", The Electronic Journal of Business Research Methods , Vol. 7 No. 1, pp. 67-74.

Pizam, A. and Jeong, G.H. (1996), "Cross-cultural tourist behaviour: Perceptions of Korean tour-guides”, Tourism Management, Vol. 17 No. 4, pp. 277-286.

Rayport, J. and Jaworski, B.J. (2001), E-Commerce, McGraw-Hill, New York.

Reisinger, Y. and Turner, L. (1999), "A cultural analysis of Japanese tourists: challenges for tourism marketers", European Journal of Marketing, Vol. 33 No. 11/12, pp. 1203-1227.

Rentzel, L. (1990), Emotional Dependency, Inter Varsity Press, USA.

Riley, R.W. (1996), "Revealing Socially Constructed Knowledge Through Quasi-Structured Interviews and Grounded Theory Analysis", Journal of Travel and Tourism Marketing, Vol. 5 No. $1 / 2$, pp. 21-40.

Sachau, L. and Hutchinson, S. (2012), "Trends in culturally relevant interface design features for Latino Web site users", Education Technology Research and Development, Vol. 60 No. 6, pp. 1033-1050. 
Schwartz, S. (1999), "A Theory of Cultural Values and Some Implications for Work", Applied Psychology: An International Review, Vol. 48 No. 1, pp. 23-47.

Shaw, S. (2003), "The Client's Helical Path: A Grounded Theory of Unsucessful Therapy Experiences", Doctoral Thesis, College of Graduate Studies and Research, University of Saskatchewan.

Sigala, M. and Sakellaridis, O. (2004), "Web Users' Cultural Profiles and E-service Quality: Internationalization Implications for Tourism Web Sites", Information Technology and Tourism, Vol. 7 No. 1, pp. 13-22.

Singh, N., Zaho, H., Hu, X. (2003), "Cultural adaptation on the Web: a study of American companies' domestic and Chinese Web sites", Journal of Global Information Management, Vol. 11 No. 3, pp. 63-80.

Singh, N. and Baack, D.W. (2004), "Web site Adaptation: A Cross-Cultural Comparison of U.S. and Mexican Web sites", Journal of Computer-Mediated Communication, Vol. 9, No. 4, available at: http://jcmc.indiana.edu/vol9/issue4/singh_baack.html (accessed 25 October 2012).

Singh, N., Kumar, V. and Baack, D. (2005a), "Adaptation of cultural content: evidence from B2C e-commerce firms", European Journal of Marketing, Vol. 39 No. 1/2, pp. 71-86.

Singh, N., Park, J. and Kalliny, M. (2013), “A Framework to Localize International Business to Business Web Sites", DATA BASE, Vol. 44 No.1, pp. 56-77.

Singh, N. and Pereira, A. (2005b), The Culturally Customized Web site: Customizing Web sites for the Global Marketplace, Elsevier Inc., Oxford.

Singh, N., Zhao, H. and Hu, X. (2005c), “Analyzing the cultural content of Web sites: A cross-national comparision of China, India, Japan, and US”, International Marketing Review, Vol. 22 No. 2, pp. 129-146.

Singh, N., Fassott, G., Chao, M. and Hoffman, J. (2006), "Understanding international Web site usage: A cross-national study of German, Brazilian and Taiwanese online consumers", International Marketing Review, Vol. 23 No. 1, pp. 83-98.

Singh, N., Baack, D. W., Kundu, S. K. and Hurtado, C. (2008), "U.S. Hispanic Consumer Ecommerce Preferences: Expectations and Attitudes Toward Web Content", Journal of Electronic Commerce Research, Vol. 9 No. 2, pp. 162-175.

Sinkovics, R. R., Yamin, M. and Hossinger, M. (2007), "Cultural adaptation in cross border E-commerce: A study of German Companies", Journal of Electronic Commerce Research, Vol. 8 No. 4, pp. 221-235.

Soares, A. M., Farhangmehr, M., \& Shoham, A. (2007), "Hofstede's dimensions of culture in international marketing studies", Journal of Business Research, Vol. 60 No. 3, pp. 277-284.

Strauss, A.L. and Corbin, J. (1998), Basics of Qualitative Research: Grounded Theory Procedures and Techniques (2nd ed.), Sage Publications, Newberry Park, CA.

Tierney, P. (2000). Internet-based evaluation of tourism Web site effectiveness:

Methodological issues and survey results. Journal of Travel Research, 39 (2), 212-219.

Tixier, M. (2005), "Globalization and localisation of contents: Evolution of major Internet sites across sectors of industry", Thunderbird International Business Review, Vol. 47 No. 1, pp. 15-48.

Toms, E. G., Freund, L., Kopak, R. and Bartlett, J. C. (2003). "The effect of task domain on 
search”. In: CASCON, IBM, Toronto, pp 303-312.

Watson J.J. and Wright, K. (2000), "Consumer ethnocentrism and attitudes toward domestic and foreign products", European Journal of Marketing, Vol. 34 No. 9/10, pp. 1149-67.

Würtz, E. (2005), "A cross-cultural analysis of Web sites from high-context cultures and lowcontext cultures", Journal of Computer-Mediated Communication, Vol. 11 No. 1, available at: http://jcmc.indiana.edu/vol11/issue1/wuertz.html (accessed 25 October 2012).

Yasin, M. M. and Yavas, U. (2007), "An analysis of E-business practices in the Arab culture: Current inhibitors and future strategies", Cross Cultural Management: An International Journal, Vol. 14 No. 1, pp. 68-73.

Yates, J. F. and Lee, J.W. (1996), "Chinese Decision Making Psychology". In Bond, M.H. (Ed.), Handbook of Chinese, Oxford University Press, Hong Kong.

Zaharna, R. (1995), "Understanding Cultural Preferences of Arab Communication Patterns", Public Relations Review, Vol. 21 No. 3, pp. 241-255.

Zahedi, F.M., Van Pelt, W.V. and Song, J. (2001), "A Conceptual Framework for International Web Design", IEEE Transactions On Professional Communication, Vol. 44 No. 2, pp. 83-103.

Zaheer, S. and Zaheer A. (1997), "Country Effects on Information Seeking in Global Electronic Networks", Journal of International Business Studies, Vol. 28, No. 1, pp. 77-100. 